\title{
The Late Quaternary Flow through the Bering Strait Has Been Forced by the Southern Ocean Winds
}

\author{
Joseph D. Ortiz,* Doron Nof, ${ }^{+}$LeOnid Polyak, ${ }^{\#}$ GuIllaume St-Onge ${ }^{@}$

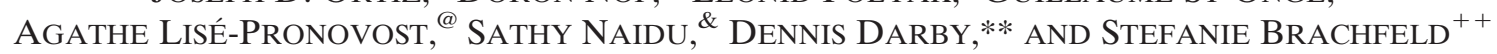 \\ * Department of Geology, Kent State University, Kent, Ohio \\ ${ }^{+}$Department of Earth, Oceans and Atmospheres, The Florida State University, Tallahassee, Florida \\ \# Byrd Polar Research Center, The Ohio State University, Columbus, Ohio \\ @ Canada Research Chair in Marine Geology, Institut des Sciences de la Mer de Rimouski (ISMER), \\ and GEOTOP Research Center, Rimouski, Quebec, Canada \\ \& Institute of Marine Science, University of Alaska Fairbanks, Fairbanks, Alaska \\ ** Department of Ocean, Earth, and Atmospheric Sciences, Old Dominion University, Norfolk, Virginia \\ ${ }^{++}$Department of Earth and Environmental Studies, Montclair State University, Montclair, New Jersey
}

(Manuscript received 2 September 2011, in final form 3 July 2012)

\begin{abstract}
Because North and South America are surrounded by water, they constitute together a gigantic island whose peripheral sea level is controlled by the winds east of the island, winds along the western boundary of the island, the freshwater flux, and the meridional overturning cell. This idea has been expressed in several articles where a series of analytical models show that the Bering Strait (BS) flow is controlled by the interplay of the Southern Winds (sometimes referred to as the "Subantarctic Westerlies"), and the North Hemisphere freshwater flux. Here, the authors report a paleoceanographic analysis of proxies in the BS as well as the Southern Ocean, which clearly support the above through employment of a slowly varying time-dependent version of the coupled Sandal-Nof model.

This study shows a very strong correlation between the Southern Ocean winds and the BS flow. A midHolocene weakening of the Southern Winds followed by the cession of freshwater fluxes from the melting Laurentide ice sheet strengthened the BS flow for several thousand years. Increasing the Southern Winds enhances the near surface, cross-equatorial flow from the Southern Ocean to the Northern Hemisphere. This cross-equatorial flow decreases the Arctic outflow into the Atlantic demonstrating a dynamic linkage between the Southern Ocean Winds and the mean flow through the BS.
\end{abstract}

\section{Introduction}

\section{a. Physical oceanographic background}

Until fairly recently, investigators of the Bering Strait (BS) flow focused on the long-strait pressure gradient without asking the question what forms that pressure gradient in the first place. Stigebrandt (1984) was the first to imaginatively argue that the flow through the BS $\left[\sim 1 \mathrm{~Sv}\left(1 \mathrm{~Sv} \equiv 10^{6} \mathrm{~m}^{3} \mathrm{~s}^{-1}\right)\right]$ is due to the atmospherically induced density difference between the Pacific and the Arctic (it evaporates over the Atlantic and precipitates over the Pacific). Accordingly, he treated the

Corresponding author address: Doron Nof, Department of Earth, Oceans and Atmospheres, The Florida State University, Tallahassee, FL 32306-4320.

E-mail: nof@ocean.fsu.edu system as an estuary. His calculation was followed by more elaborate analytical models (Shaffer and Bendtsen 1994) and a series of local and global numerical experiments (e.g., Overland and Roach 1987; Hu et al. 2007, 2010). In line with these studies, the main understanding has been that local winds are responsible for the local pressure gradients and, hence, the flow. In contrast, using contours integrals in uncoupled ocean-atmosphere models, Nof (2000), Nof and Van Gorder (2003), and De Boer and Nof $(2004 a, b)$ argued that the mean sea level difference along the strait is setup by the global winds, particularly the strong Southern Winds (i.e., zonal winds along a latitudinal band connecting the tip of South America and Cape Town, which are also referred to as the Subantarctic Westerlies).

Although the BS is merely $\sim 50 \mathrm{~m}$ deep and $\sim 100 \mathrm{~km}$ broad, the $1 \mathrm{~Sv}$ that goes through it does not even come 
close to its hydraulic limit, which is one or two orders of magnitude larger (see e.g., Chaudry 1993 for details on hydraulic control). Similarly, as shown in De Boer and Nof (2004a), the form-drag exerted by the sill (in the BS) on the flow is not large enough to restrict the flow in any meaningful way. The mean flow state within the BS state appears to be independent of the local winds, but the local winds control the variability of the flow (Woodgate et al. 2006, and the references given therein). Of course, all of these estimates are based on measurements conducted over a period of merely 50 years. The paleoceanographic data that we will be working with here provides for the first time, an opportunity to examine these processes over a much longer period of $\sim 12000$ calendar years before present (cal BP).

\section{b. Models and paleoceanographic background}

Here, we use a time-dependent version of the coupled analytical model of Sandal and Nof (2008b, hereafter $\mathrm{SN})$. To do this, we invoke the slowly varying approach, where a steady model solution is taken to be valid when the forcing varies on a time scale much longer $(\sim 1000 \mathrm{yr})$ than the time scale of interest $(\sim 10 \mathrm{yr})$. The simplicity of the model, which incorporates only the fundamental physics needed to model the interaction of the winddriven and the thermohaline circulation enables us to run the model with 100-yr time steps for a period of 12000 years. As described below, we force the model with paleoceanographic proxies for the Southern Winds and the Northern Hemisphere freshwater flux, and evaluate the solution using an additional paleoceanographic record detailing the flow through the BS, not included in the model.

The locations of the cores from which these proxy records were extracted are shown in Fig. 1. The Palmer Deep site is located off the Antarctic Peninsula, not in Drake Passage proper. Analysis of the modern wind field indicates that it is highly correlated throughout the South Atlantic sector of the Southern Ocean. Most importantly, however, Nof et al. (2011) present a synthesis of the paleosouthern wind data suggesting that their approximately linear relationship holds on longer time scales as well. (Specifically, they examined the variations in the strength of the Agulhas retroflection during glacial periods.)

As we shall see, regression of our chlorite proxy against the model output provides a useful way of scaling the results into familiar units (because the paleo-proxy is based on standardized scores). The units of the comparison do not, however, affect the correlation between the paleoceanographic proxy and the model output because Pearson's correlation is dimensionless.

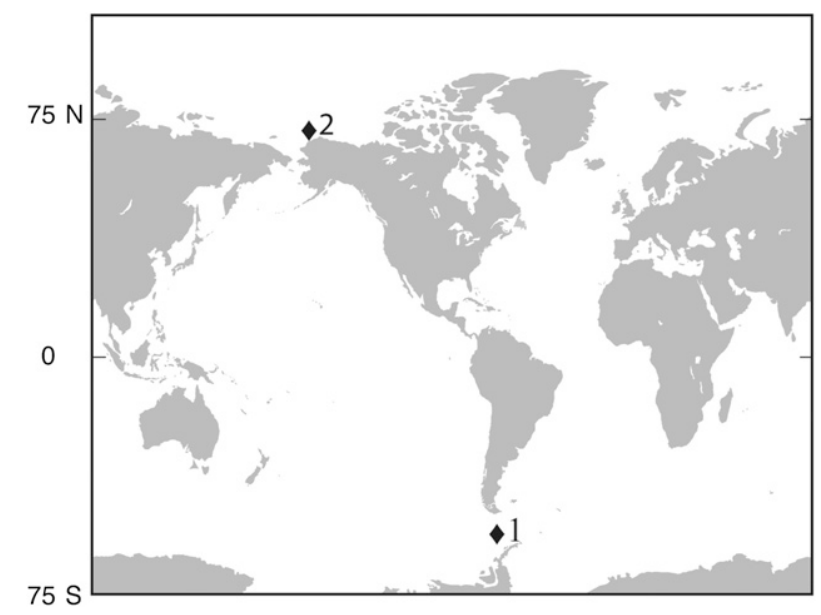

FIG. 1. A global map showing the location of two cores used in the study. They provide proxies for the following: 1) Southern Winds (Palmer Deep core; Domack et al. 2001), and 2) flow through the BS (core HLY0501-JPC6 from Ortiz et al. 2009).

Woodgate et al. (2010) note that the local winds act to slow the flow through BS by 0.4 to $0.2 \mathrm{~Sv}$ (out of a mean flow of $\sim 0.8 \mathrm{~Sv}$ ). Note, however, that Nof et al. [2011, autonomous underwater vehicle (AUV) glider and HF radar observations of circulation and stratification features in the Chukchi Sea, Ocean Sciences Meeting, 20-24 February 2012, Salt Lake City, Utah] concluded that the average magnitude of the through flow is closer to $\sim 1.1 \mathrm{~Sv}$. The local winds thus account for, at the most, $18 \%-36 \%$ of the mean flow. These values are similar to the paleo results that we shall later obtain and suggest that the uncertainty in our estimates is roughly $20 \%$. Note that this comparison across time scales also argues in favor of a linear response of the flow through BS to the Southern Winds.

The SN model is based on the contour integrals first proposed by Nof (2000), and then later used by the uncoupled models of Nof and Van Gorder (2003) and De Boer and Nof $(2004 a, b)$. We show that the SN findings are consistent with a paleoceanographic proxy for the flow through the BS from 12000 cal BP to present (Ortiz et al. 2009). We observe a period of enhanced flow into the Arctic from 6000 to $3000 \mathrm{cal} \mathrm{BP}$, which occurred when the Southern Winds were weaker and the Northern Hemisphere freshwater fluxes were minimal following a lag time of several thousand years (dictated by the small vertical diffusivity of the ocean). The SN model provides a means of evaluating the global forcing and processes that drove the variations in flow through the BS during the Holocene. The shift in Southern Winds controls most of the flow through the BS. The difference between the SN model flow prediction and the paleo-BS flow record provides a measure 
of the contribution of local forcing to the flow through BS during the Holocene. This represents the first quantitative reconstruction of paleoflow through the BS, consistent with an underlying, theoretical physical oceanographic basis.

This paper is organized as follows: In section 2 we briefly review the $\mathrm{SN}$ model. In section 3 the model results are described, and in section 4 the outcome is summarized and discussed. Section 2 makes this paper self-contained. The reader who is anxious to see the final results without going through the detailed document is referred to the figures incorporated into section 5 where a remarkable correlation between the BS paleoflow variability and the Southern Winds variability is presented. The results are summarized in section 6 .

\section{The Sandal-Nof analytical BS model}

The SN coupled ocean-atmosphere analytical model (Fig. 2) consists of six algebraic equations that are reproduced here for completeness. The first two are for the ocean and are based on the integrated momentum equations around the continental island formed by the Americas with convection to its east:

$$
\begin{aligned}
& Q_{1}=\frac{\oint \tau^{r} d r+\rho_{0} f_{2}\left(W-F_{f}\right)}{\rho_{0}\left(f_{2}-f_{1}\right)}, \\
& W=Q_{1}+Q_{2}+F_{f},
\end{aligned}
$$

where $Q_{1}$ and $Q_{2}$ are the (unknown) upper-ocean volume fluxes into the box, $W$ is the (unknown) outgoing deep-water volume flux, and $F_{f}$ is the (known) freshwater flux into the region of convection. The (known) wind stress along the counterclockwise integration contour shown in Fig. 2 is given by $\tau^{r}$, while $f_{1}$ and $f_{2}$ are the Coriolis parameters along the southern and northern boundary of the integration region and $\rho_{0}$ is a reference density. Equation (1) is simply an application of the modified island rule (with convection east of the island) to the Americas (Godfrey 1989), which was discussed earlier in the series of articles mentioned in the beginning of the introduction. It is tempting to think that contours other than the one shown in Fig. 2 could also be chosen, but it can be shown that all other contourssuch as those surrounding the Pacific or Asia-bring in additional unknowns (e.g., meridional flow in the Pacific) for which there are no analytical solutions (Nof 2000).

Related aspects of island rule calculations can be found in (Pedlosky et al. 1997; Spall 2000; Pratt and Spall 2003). Because the integration contour does not
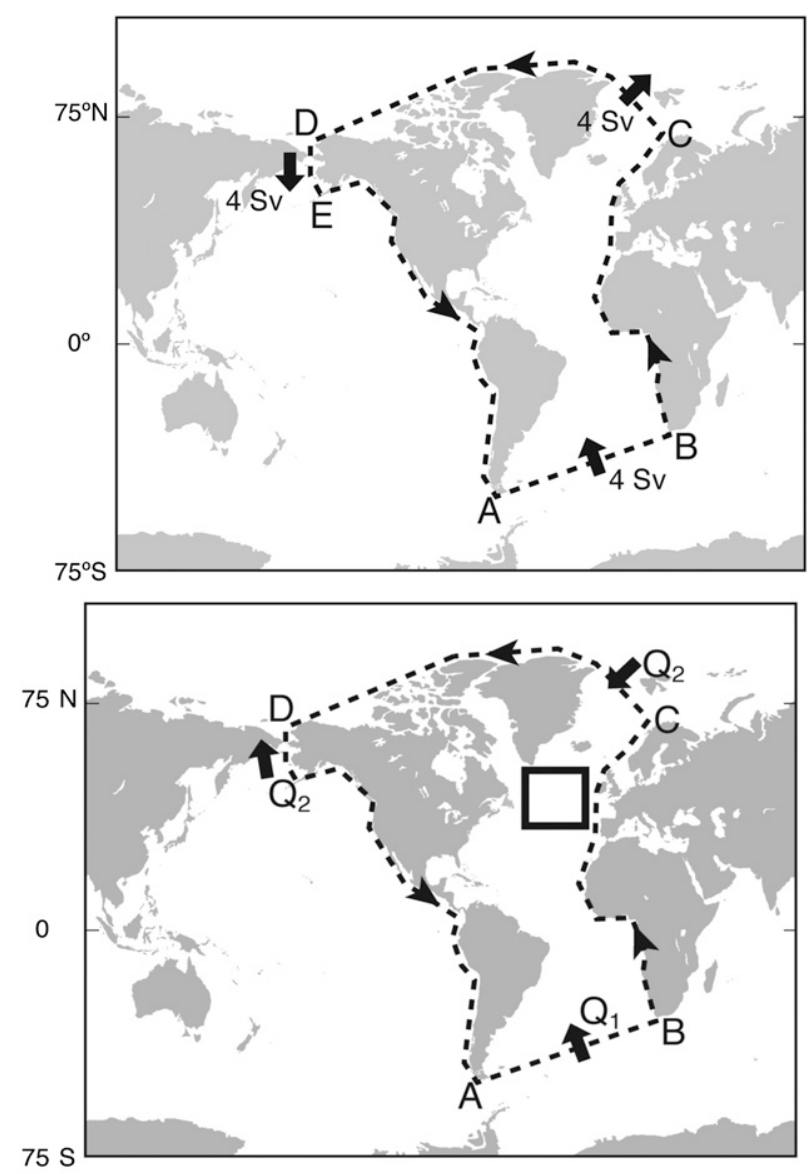

FIG. 2. (top) The flow pattern and the contour integral for the case of no deep-water formation in the Atlantic (adapted from Nof 2000). As shown in Fig. 3, most of the contribution to the 4-Sv integral comes from the Southern Winds. The winds over the Arctic and North Atlantic are so weak compared to the Southern Winds that altering the integration path in the Arctic makes virtually no difference. (bottom) The flow pattern under the same conditions but with NADW greater than $4 \mathrm{~Sv}$ (adapted from Sandal and Nof 2008a; was also used earlier by De Boer and Nof (2004a,b) and Nof and Van Gorder 2003 for different conditions). Here, $Q_{1}$ and $Q_{2}$ are the upper layer (above Atlantic topography) transports into the Atlantic from the south and north, respectively.

cut through the deep-water formation region, it is permissible to include (the unknown) $W$ in the island calculation. Also, note that the particularly chosen contour, as well as the distribution of vorticity, only affects how the net flow is partitioned between the Sverdrup interior and the western boundary current east of the island. Neither the vorticity nor the chosen contour affect the mean net flows $\left(Q_{1}\right.$ and $\left.Q_{2}\right)$, which are the variables of interest here. It is precisely because one does not have to worry about the contour (or vorticity) that circulation theorems of the kind used here are so powerful. 
The next two equations for the ocean are the salt and heat conservation equations:

$$
\begin{aligned}
Q_{1}\left(S_{1}-S\right)+Q_{2}\left(S_{2}-S\right) & =S F_{f}, \quad \text { and } \\
Q_{1}\left(T_{1}-T\right)+Q_{2}\left(T_{2}-T\right) & =\frac{A}{\rho_{w} C_{p w}}\left(F_{S}+F_{L}\right),
\end{aligned}
$$

where $S$ is the (unknown) convection salinity in the box, and $S_{1,2}$ are the (known) salinities of $Q_{1,2}$ (respectively). The conservation of salt equation for the case with an open Bering Strait (employed here) differs in an important way from that of the model with a closed Bering Strait (Sandal and Nof 2008a). Note that an increase in $F_{f}$ does not necessarily mean that $\mathrm{S}$ will decrease because an increasing $F_{f}$ can be compensated for by a stronger decrease of $Q_{2}$ with the ultimate result of an increasing $S$.

In the heat Eq. (4), $T$ (unknown) is the mean temperature in the convection box, whereas $T_{1,2}$ are the (known) temperatures of the (unknown) entering flows $Q_{1,2}$. Following Hartmann (1994), $F_{S}=\rho_{a} C_{p a} C_{S} U_{10}\left(T_{\text {mean }}-T_{\text {air }}\right)$ is the sensible heat flux, whereas $F_{L}=\rho_{a} L_{e} C_{L} U_{10} q^{*}$ $\left(1-R_{H}\right)+\rho_{a} C_{L} U_{10} R_{H}\left(C_{p a} / B_{e}\right)\left(T_{\text {mean }}-T_{\text {air }}\right)$ is the latent heat flux. The relationship for the mean air temperature above the box is $T_{\text {air }}=\left(T_{\mathrm{ai}}+T_{\mathrm{ao}}\right) / 2$. Here, $T_{\mathrm{ai}}$ (known) and $T_{\text {ao }}$ (unknown) are the incoming and outgoing air temperatures of the eastward flowing atmospheric jet. The area of the box (known) is $A\left(\mathrm{~m}^{2}\right)$, whereas $\rho_{w}$ and $\rho_{a}\left(\mathrm{~kg} \mathrm{~m}^{-3}\right)$ represent the (known) densities of water and air, and $C_{p w}$ and $C_{p a}\left(\mathrm{~J} \mathrm{~kg}^{-1} \mathrm{~K}^{-1}\right)$ are the specific heat capacities of water and air. The fluxes, $F_{S}$ and $F_{L}\left(\mathrm{~W} \mathrm{~m}^{-2}\right)$ denote the sensible and latent heat fluxes, $C_{S}$ and $C_{L}$ are constants, $U_{10}\left(\mathrm{~m} \mathrm{~s}^{-1}\right)$ is the wind speed at $10 \mathrm{~m}$ above the surface, $q^{*}\left(\mathrm{~g} \mathrm{~kg}^{-1}\right)$ is the saturation specific humidity of the air, and $L_{e}\left(\mathrm{~J} \mathrm{~kg}^{-1}\right)$ is the latent heat of evaporation. The relative humidity of the air is $R_{H}$, whereas $B_{e}$ is the equilibrium Bowen ratio (Hartmann 1994), and $T_{\text {mean }}$ is the average sea surface temperature within the box, $\left(T_{\mathrm{wi}}+T_{\mathrm{wo}}\right) / 2$. Radiative fluxes are neglected in (4) because, as pointed out by Nof et al. (2011, section 8), radiative fluxes are not important to the turning of the Atlantic meridional overturning circulation (AMOC) on and off.

The main difference between the coupled SN model and the uncoupled De Boer and Nof (2004a) model is the term on the right hand side of (4), which is the ocean-atmosphere coupling heat-flux term. It is fixed in De Boer and Nof (2004a) implying a fixed heat flux to the atmosphere regardless of the meridional overturning cell strength. By contrast, it is variable in SN implying that the ocean and atmosphere work in concert.

The fifth oceanic equation is the convection condition developed by De Boer and Nof (2004a,b),

$$
T=T_{D}+\frac{\beta}{\alpha}\left(S-S_{D}\right)
$$

where $\alpha$ and $\beta$ are the familiar expansion coefficients, and $T_{D}$ and $S_{D}$ are the (known) temperature and salinity of the deep layer beneath the box. The sixth equation is an air-sea closure condition stating that the oceanic and atmospheric mass transports are the same. This is certainly the case in the Ekman layers and it was assumed in SN that it is also true for the entire air and ocean mass fluxes participating in the air-sea heat exchange process. As stated in SN, this simply implies that the horizontal atmospheric temperature changes are related to the horizontal oceanic changes through the specific heat-capacity ratio,

$$
T_{\mathrm{ao}}-T_{\mathrm{ai}}=\frac{C_{p w}}{C_{p a}}\left(T_{\mathrm{wi}}-T_{\mathrm{wo}}\right) .
$$

In (6), $T_{\mathrm{ai}}\left(T_{\mathrm{wi}}\right)$ and $T_{\mathrm{ao}}\left(T_{\mathrm{wo}}\right)$ are the (known) temperatures of the incoming and (unknown) outgoing air (water) within the box. We shall associate $T_{\mathrm{wi}}$ (known) with the temperature of the incoming water from the south $\left(T_{1}\right.$, known) and $T_{\text {wo }}$ (unknown) with the convective water temperature $T$. The air/water specific heat capacities ratio is roughly $1: 4$, suggesting that the atmospheric variations are roughly four times the oceanic variations, in agreement with the observed changes during the last deglaciation displayed by the figures presented by Bard (2002). The model thus gives a set of six algebraic equations for the six unknowns: $T, S, T_{\mathrm{ao}}, Q_{1}, Q_{2}$ and $W$.

Equations (3) and (4) are nonlinear because they involve multiplications of the unknowns. Despite this nonlinearity, the flow regime is reversible as long as: (i) the AMOC does not completely collapse because of too large a freshwater input, and/or (ii) $Q_{2} \geq 0$. When $Q_{2}<0$ the governing equations need to be rewritten because the flow in the BS is from the Arctic to the Pacific implying that the salinity of the Pacific $S_{2}$ is no longer relevant. While this is straightforward to do, it is not worthwhile for what we want to achieve here, as we shall see later. We solve these equations using an iteration scheme because an attempt to eliminate some of the unknowns to form a single equation with one unknown yields a complex nonlinear equation, which cannot be solved easily.

\section{The SN model output as a function of winds and freshwater flux}

The SN analytical model suggests that the BS and the strong Southern Winds are intimately connected. 


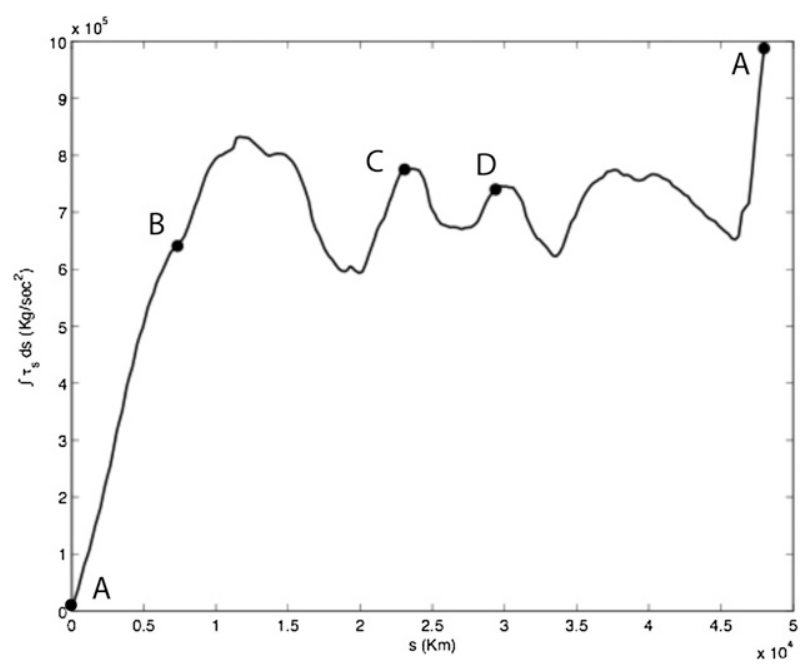

FIG. 3. Cumulative wind integral of $\left(\tau^{r} d r\right)$ around the North and South American continents. The integral is composed of four sections, delineated by the filled dots. Section AB is from the southern tip of S. America to the southern tip of Africa, Section BC is from the southern tip of Africa to Norway, Section CD is from Norway to the Bering Strait, and Section A is from the Bering Strait back to the southern tip of S. America (see Fig. 2).

Because of the stratification in the North Atlantic and the small vertical diffusivity $\left(\sim 0.1 \mathrm{~cm}^{2} \mathrm{~s}^{-1}\right)$, the Atlantic is not large enough to allow compensating upwelling within its own limits. To sustain its surface flow, the AMOC must draw water from a much larger region outside the Atlantic itself (e.g., the Southern Ocean), providing a dynamical link to the Southern Winds (Nof et al. 2007). In the absence of North Atlantic Deep Water (NADW) formation (i.e., $W=0$ ), the model reduces to the configuration shown on the top panel of Fig. 2, which is merely a reproduction of a figure shown earlier in Nof (2000) involving a simple flow around an island formed by the Americas. Because of north-south asymmetries, the modern Southern Winds (with no NADW) would transport about $4 \mathrm{~Sv}$ from the South Atlantic $\left(Q_{1}\right)$ northward through the Atlantic and Arctic basins and into the Pacific via the BS. As stated, the solution for this limiting case (upper panel of Fig. 2) is obtained simply by setting $W=0$ in (1) and (2). Note the $f$ is taken to be constant along AB but, as mentioned in Nof (2000), this introduces errors of less than $25 \%$.

Figure 3 shows the resulting wind integral $\left(\oint \tau_{s} d s\right)$ illustrating that more than $80 \%$ of the integral comes from the very strong Southern Winds blowing along $A B$ and the region immediately to the north of $\mathrm{B}$. When the NADW formation rate exceeds $4 \mathrm{~Sv}$, the flow through the BS $\left(Q_{2}\right)$ reverses, correctly representing the modernday flow into the Arctic. As shown in Fig. 4, the flow from the Southern Ocean depends on the strength of the Southern Winds and freshwater fluxes at the convection site. This, in turn, determines the magnitude of the flow out of the Arctic through the BS $\left(Q_{2}\right)$ and the sinking flux $(W)$. The above "predicted" flow reversals through the BS and Fram Strait have been verified numerically in a global, coupled GCM (Hu and Meehl 2005; Hu et al. 2007).

To evaluate the parameter space of the model, we examined several model outputs in which we vary the freshwater flux $\left(F_{f}\right)$ and the magnitude of the Southern Winds in a smooth hypothetical manner (Fig. 4). (Later on, in section 5, we will force the model with actual winds variability but this is not our focus right now.) The model implies that $Q_{1}$ and $Q_{2}$ are inversely correlated with the wind forcing in the south (Fig. 4, upper panels). As the winds increase, from zero to the strength of the modern winds, the temperature of the North Atlantic increases (Fig. 4 lower left panel) and the AMOC strength increases because of the enhanced cross equatorial flux of warm and salty surface water $\left(Q_{1}\right)$ toward the North Atlantic. Heat loss to the atmosphere of this warm and salty water (during winter convection) results in water denser than the colder, fresher water from the north $\left(Q_{2}\right)$.

Changing the freshwater flux $\left(F_{f}\right)$ from zero to $0.03 \mathrm{~Sv}$ changes the magnitude of $Q_{1}$ and $Q_{2}$ but does not influence their dependence on the wind forcing (Fig. 4). In contrast, $F_{f}$ does alter the relationship between the winds and North Atlantic temperature (Fig. 4, lower left panel) and between the AMOC and the Southern Winds (Fig. 4, lower right panel). Specifically, the gradient of the North Atlantic temperature dependency on the Southern Winds becomes steeper as freshwater fluxes increase (Fig. 4, lower left panel). For high freshwater flux, the AMOC increases with increasing wind strength, whereas for low freshwater flux, the AMOC weakens slightly with increasing wind strength (Fig. 4, lower right panel). This weakening occurs because stronger winds bring greater amounts of warm cross-equatorial water into the North Atlantic, decreasing surface density and making convection more difficult. Accordingly, decreasing the Southern Winds decreases the cross-equatorial flux, cooling the North Atlantic by increasing the relative proportion of $Q_{2}$, the Arctic water entering the North Atlantic.

Note that the rate at which sea level rose is proportional to the derivative of the sea level curve, which we used as a linear measure of freshwater input to the global ocean. Because our model employs a 100-yr time step and integrates over the ocean basin, there is ample time for the freshwater flux to be well mixed. We assumed that $70 \%$ of the sea level rise was due to melting of Northern Hemisphere ice and scaled the input into the Atlantic relative to its surface area. The intercept for the relationship is a tunable parameter set to a minimal value consistent with modern freshwater flux as expressed in the model. 

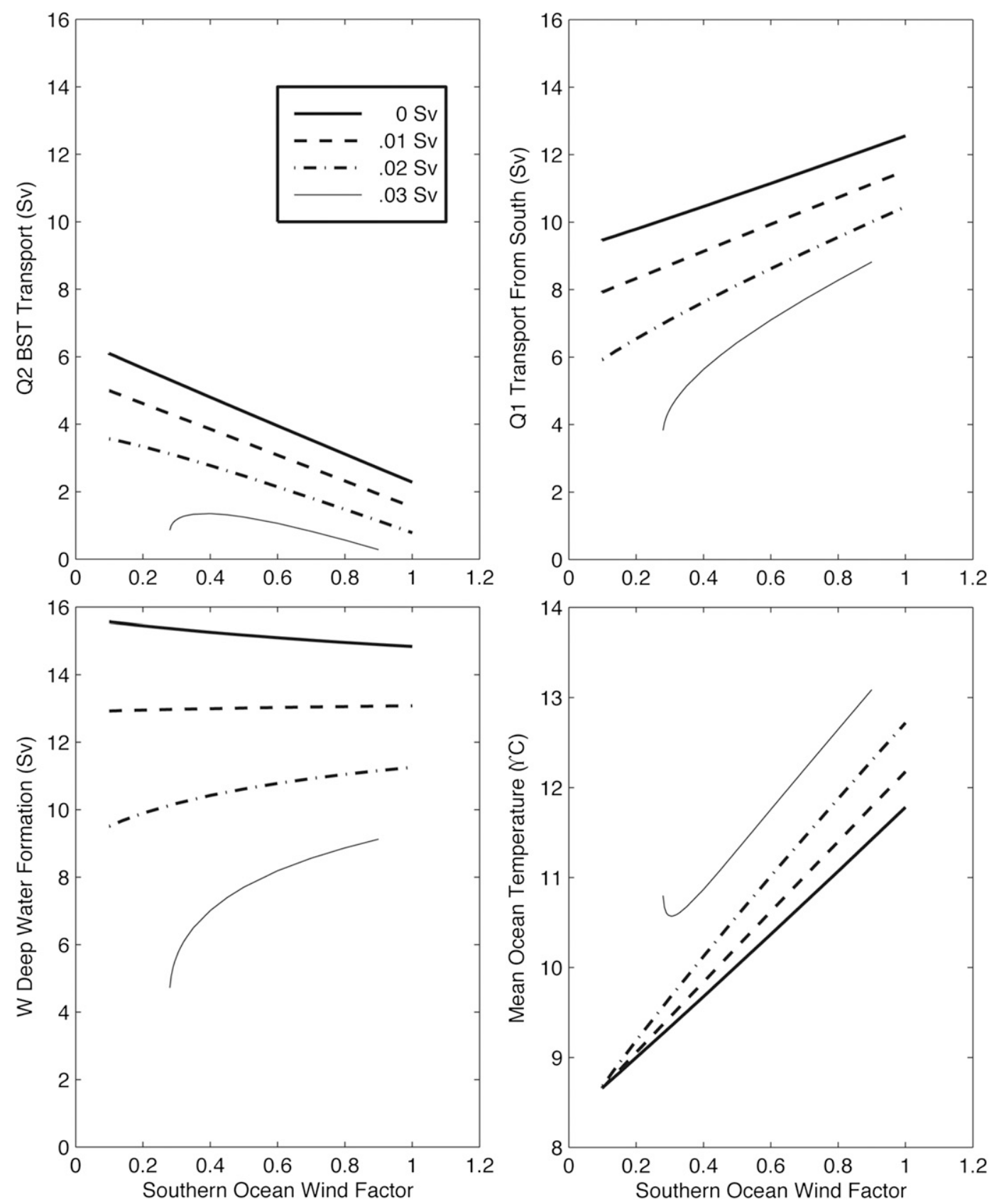

FIG. 4. (top left) The SN solution for the flow through the BS $\left(Q_{2}\right)$, (top right) the transport from the Southern Ocean $\left(Q_{1}\right)$, (bottom left) the rate of deep-water formation $(W)$, and (bottom right) the mean ocean temperature as a function of the (assumed steady) Southern Winds strength (horizontal axis) for various rates of freshwater flux (see inset). The thin solid line is the solution most closely related to the preset day conditions. Today's wind corresponds to a wind factor of unity.

\section{Paleoceanographic records}

\section{a. Wind variability during the Holocene}

We focus on the last 12000 cal BP because this is the most recent interval during which sea level was high enough for an open BS (Keigwin et al. 2006). Published paleoclimate data from two locations around the globe (Fig. 1) provide us with a means of testing the SN analytical model by comparing its results to past climate system variation. The magnetic susceptibility record from Palmer Deep (Domack et al. 2001) provides a useful measure of the strength of the Southern Winds during the past 12,000 cal BP. Located on the continental shelf along the Antarctic Peninsula, 
Palmer Deep is well situated for monitoring these winds.

The magnetic susceptibility signal recorded in sediment from Palmer Deep is correlated with enhanced delivery of ice-rafted debris (IRD) and the dilution effects of biogenic silica, with the latter factor related to wind strength. During cool, windy intervals the water column is well mixed, which forces phytoplankton down below the photic zone, limiting productivity and the flux of biogenic silica to the seafloor. By contrast, during warmer intervals with melting sea ice and reduced winds, the upper water column is strongly stratified, allowing phytoplankton to remain in the photic zone, increasing productivity and increasing the flux of biogenic silica to the seafloor (Leventer et al. 1996, 2002). The increase in biogenic silica dilutes the terrigenous component of the sediment, creating intervals of low magnetic susceptibility. Evidence of this relationship between magnetic susceptibility driven by terrestrial derived grains and stratification-controlled biogenic silica production can also be seen in the North Pacific over longer time scales (Haug et al. 1999).

Comparison of surface sediment magnetic susceptibility measurements across Drake's Passage suggest that when the modern winds vary by a factor of two across the latitudinal range from $40^{\circ} \mathrm{S}$ to $60^{\circ} \mathrm{S}$ (Hellerman and Rosenstein 1983), magnetic susceptibility varies by two orders of magnitude in response to biogenic dilution (Pirrung et al. 2002). The relative changes in wind strength inferred from the Palmer Deep record (Fig. 5, upper panel) are also correlated with changes in pollen and sediment elemental ratios from South America. These are believed to arise from variations in the Southern Winds, supporting the above interpretation of the Palmer deep record (Gilli et al. 2005; Heusser et al. 2006; VillaMartínez and Moreno 2007; Muratli et al. 2010).

\section{b. Freshwater fluxes during the Holocene}

Citing prior results from the uncoupled island model of De Boer and Nof (2004a) and Keigwin and Cook (2007) postulated that a freshening of the North Atlantic would tend to weaken the AMOC. However, they focused on cross-basin atmospheric water vapor transport from the Atlantic to the Pacific. While this creates the salinity difference between these oceans, it is not directly related to the changes discussed here. Here, we evaluated net global freshwater fluxes during the deglaciation by calculating the time rate of change of sea level from the deglaciation to present using the sea level curve of Milne and Mitrovica (2008). This integrates net changes in freshwater fluxes (Fig. 5, lower panel), the majority of which enter the ocean in the Northern Hemisphere.

\section{c. Bering Strait flow variability during the Holocene}

To monitor temporal changes in the flow through BS, we use a proxy based on the concentration of chlorite + muscovite inferred by visible derivative spectroscopy of a series of cores along the Alaskan Chukchi shelf (Ortiz et al. 2009). In the Western Arctic, chlorite mostly enters the Chukchi Sea from the Pacific, carried by currents or incorporated in sea ice flowing through the BS. Because chlorite is the dominant clay mineral in the NE Pacific and illite is the dominant clay mineral in the NE Chukchi Sea (Naidu and Mowatt 1983), increases in the concentration of chlorite on the continental shelf near Barrow Canyon are interpreted to indicate enhanced flow from the Pacific to the Arctic via the BS (Ortiz et al. 2009).

We selected core HLY0501-JPC6 raised from a location west of Barrow Canyon on the Alaska Chukchi Margin as the ideal core for this study because it contains the highest concentration of chlorite in a suite of eight cores (Ortiz et al. 2009). These cores were collected over a $1200-\mathrm{m}$ range of water depths with an average vertical spacing of $\sim 300 \mathrm{~m}$ between cores (Ortiz et al. 2009; Ortiz. 2011). The close proximity of these cores allows us to use them to generate vertical profiles documenting local variations in clay mineral distribution versus water depth (Ortiz. 2011). The relative contribution of chlorite in the sediment increases with depth into the Atlantic layer (200$900 \mathrm{~m}$ ), reaching a maximum at $673 \mathrm{~m}$, the depth of core JPC6, then decreases with depth for cores located within the cold salty bottom water $(>900 \mathrm{~m})$. The thickness of the postglacial sedimentary unit generally decreases with water depth on the Chukchi Margin. Exceptions are cores from a relatively steep part of the slope between 500$600 \mathrm{~m}$. Here, sediment is either not accumulating rapidly or is lost because of a variety of sediment transport processes. These are as follows: winnowing by variable current strength (which is typically constrained by potential vorticity conservation), focused settling of particles from the Pacific layer above, and down slope transport by dense winter waters cascading via cross-shelf canyons. Weingartner et al. $(1998,2005)$ found that brine rejection produced water capable of penetrating a few hundred meters depth. Deeper downwelling flows are probably generated by the transformation of brine-rejected flows to sediment-laden, nepheloid flows down canyons (Eittreim et al. 1982). The distribution of these nepheloid flows to greater depth is very poorly known; they are likely concentrated along narrow depth intervals, such as the depth horizon sampled by JPC6.

\section{Model-data comparison}

For this comparison we made three different, timedependent runs, which are referred to as runs 1,2 , and 3 . 

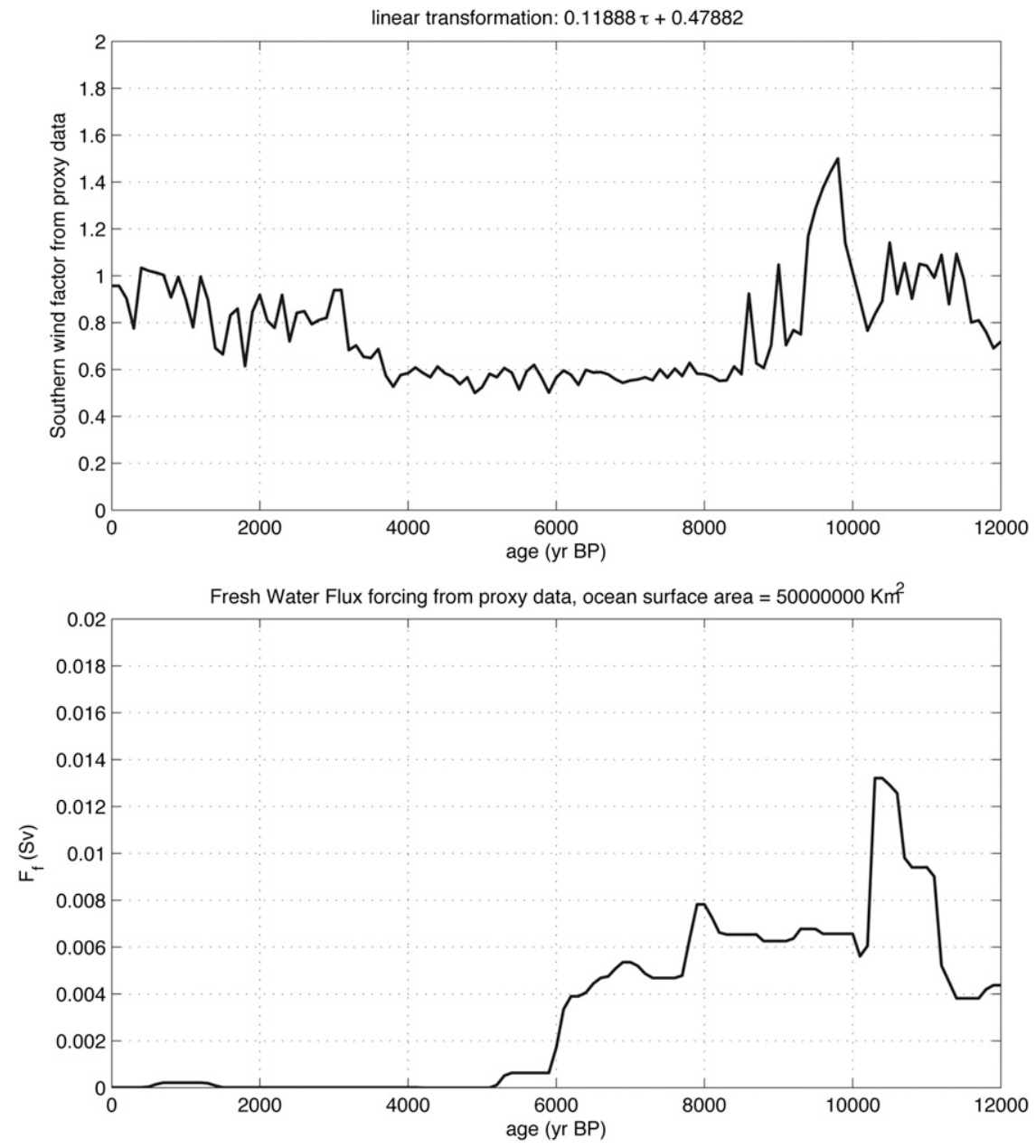

FIG. 5. (top) The slowly varying wind forcing adopted from the proxies and (bottom) the slowly varying freshwater flux adopted from sea level variations. These forcing were used with the steady SN model to produce the results shown below (referred to as Run 1, which is a run where both the wind and freshwater were specified as the data suggests).

We used the same numerical parameters values that were used by SN except that, to reflect present day conditions, $S_{1}=35.4 \mathrm{psu} ; U_{10}=3.0 \mathrm{~m} \mathrm{~s}^{-1} ; \mathrm{Be}=0.4 ;$ and $q_{s}=0.014 \mathrm{~g} \mathrm{~kg}^{-1}$ were changed to $S_{1}=35.2 \mathrm{psu} ; U_{10}=$ $5.0 \mathrm{~m} \mathrm{~s}^{-1} ; \mathrm{Be}=0.65$; and $q_{s}=0.010 \mathrm{~g} \mathrm{~kg}^{-1}$, which are the same as those used in Nof et al. (2010, page 12, bottom of their section 4). These values produce a relatively high $Q_{2}$, which minimizes negative flow conditions in agreement with the paleoceanographic results.

In the first run, we forced the model with both the proxy-determined wind variability and the proxydetermined freshwater variability (Fig. 5). The results of this run are shown in Fig. 6. Note that the empty gap represents a single time step where the flow through the $\mathrm{BS}$ is negative so that our present model equations do not apply. We shall see shortly that our results display a dramatic correlation between the "predicted" (i.e., model outcome) volume flux through the BS and the paleoceanographic estimate of the flux over the last $12000 \mathrm{cal}$ BP. To verify that this strong correlation is indeed a result of the wind variability and not the freshwater variability, we made two more runs. For Run 2 we adopted a forcing where the wind was held constant, but the paleoceanographic freshwater flux varied (Fig. 7). We see from the results displayed in Fig. 8 that $Q_{2}$ does not show much variability suggesting that freshwater is not the agent responsible for the $Q_{2}$ correlation with the Southern Winds (shown earlier in Fig. 6). Furthermore, 

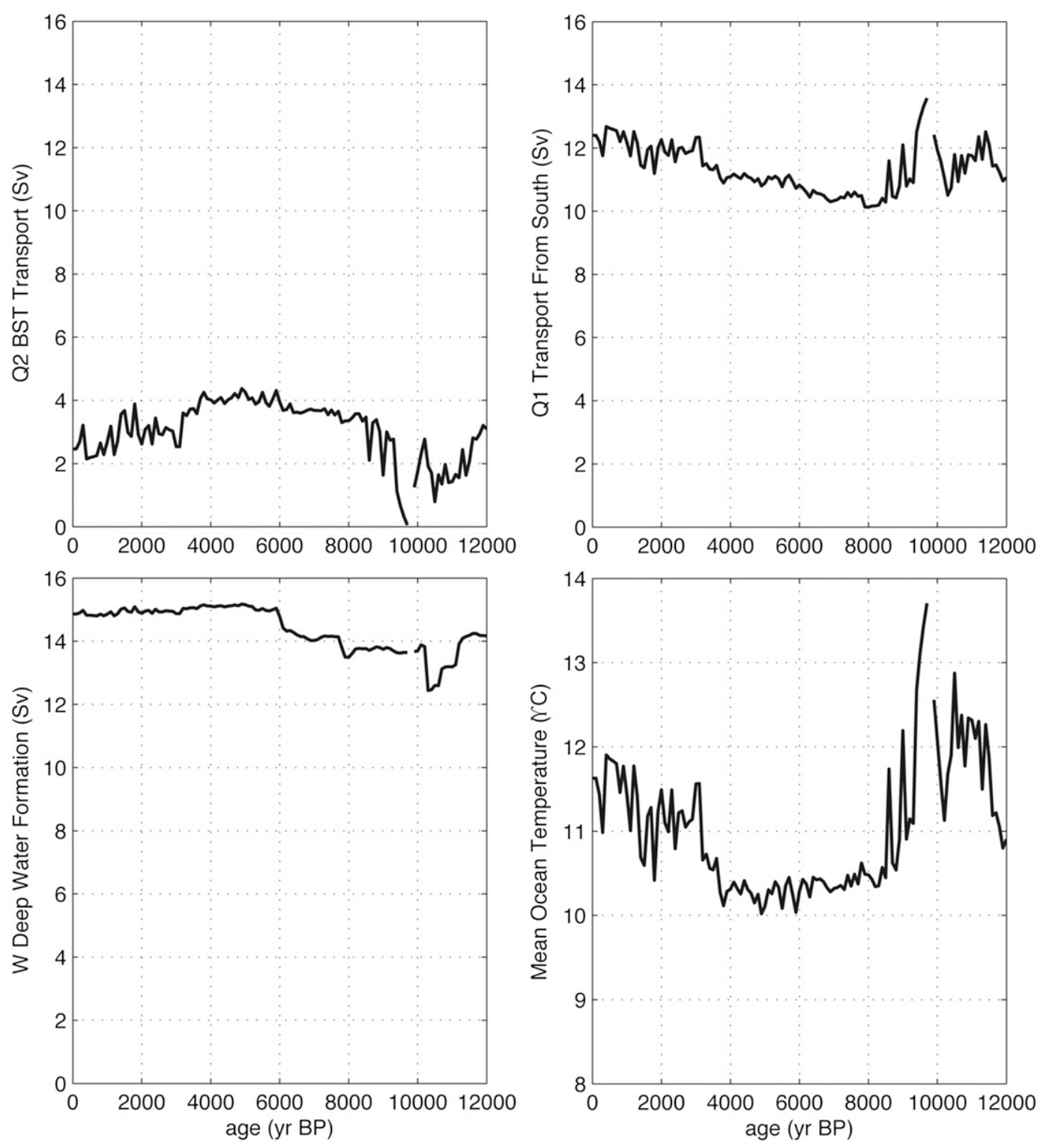

FIG. 6. The SN model results for the forcing shown above in Fig. 5 as a function of time (instead of as a function the wind stress strength that was shown in Fig. 4). The gap from $9300 \mathrm{Cal} \mathrm{BP}$ to $9600 \mathrm{Cal} \mathrm{BP}$ results from the reversal of the BS flow, whose details were not calculated here. Namely, during that period $Q_{2}$ is negative implying that to get the detailed solution one has to rewrite the equations and solve a different set of equations. This is beyond the scope of this study.

this run suggests that freshwater fluxes are much less important to the BS flow than the Southern Winds. We reconfirm this by conducting another run (Run 3) where the freshwater was held constant but the paleowinds were varied (Fig. 9). For this case we see that the observed variability in $Q_{2}$ is recovered (Fig. 10) indicating that it is the wind, not the freshwater flux, which is responsible for the variability of the flow through the BS.
The results shown in Fig. 6 could, in principle, be compared to the observed variability of $Q_{2}$ as well as the observed variability of $Q_{1}$ and W (representing the AMOC since, for most cases, $\left.Q_{2} \ll Q_{1}\right)$. In practice, a comparison to $Q_{2}$ is much easier to do than a comparison to the AMOC because the flow through the BS occurs over a small, shallow and well defined area whereas the AMOC and its sinking occurs over deep, larger and a relatively 

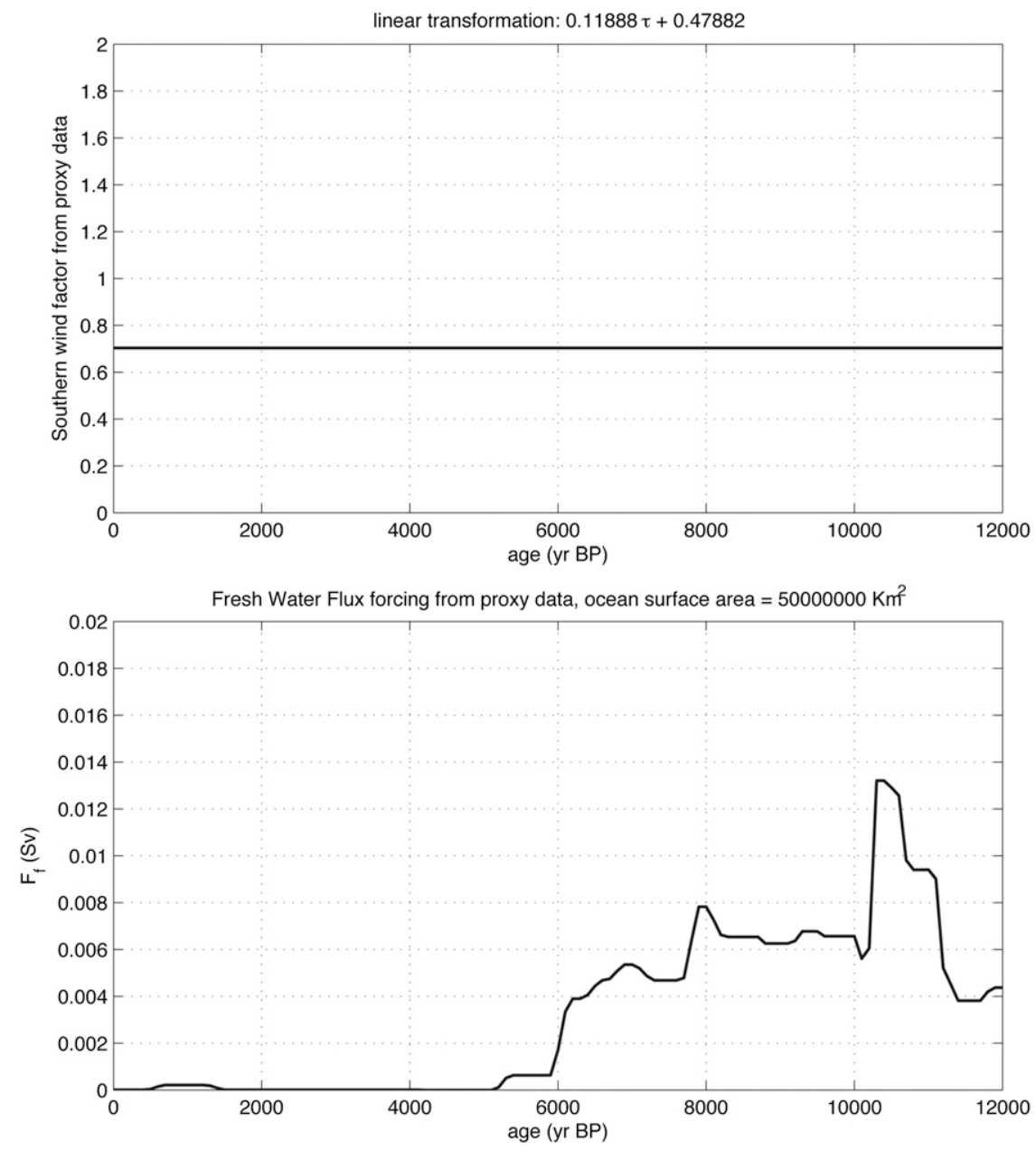

FIG. 7. The hypothetical forcing of variable freshwater flux but steady winds used for Run 2 .

poorly defined area. It is for this reason that we focus here on the BS and leave the comparison to the AMOC as a subject of another investigation.

\section{Discussion and summary}

\section{a. Role of the BS}

Prior numerical modeling work has demonstrated that the AMOC is sensitive to the Southern Winds (Toggweiler and Samuels 1993, 1995) as well as to freshwater fluxes. The analytical model we use here is a convenient and transparent tool to study the impact of the BS on Holocene climate because it includes the most critical dynamics without adding unrelated and unnecessary complexity. This simplicity allows us to run the model in a timedependent way that is not possible with more complex models. In the SN model, the flux through the BS into the Arctic $\left(Q_{2}\right)$ increases as $F_{f}$ decreases. Enhanced flow through the BS into the Arctic Ocean exports fresher, Pacific water into the North Atlantic with the potential to weaken the AMOC by changing salinity in the North Atlantic deep-water formation region. During low stands, sea level drops of more than $50 \mathrm{~m}$ close the BS, isolating the Pacific and Arctic Oceans. (These cases are not discussed here but see Sandal and Nof 2008c and the references given therein.) As the winds increase, a larger freshwater flux is required to weaken or shut down the AMOC.

\section{b. Time-dependent changes in the BS flow}

The flow from the Pacific into the Arctic through the BS increased gradually from 10000 to $8000 \mathrm{cal} \mathrm{BP}$, and 

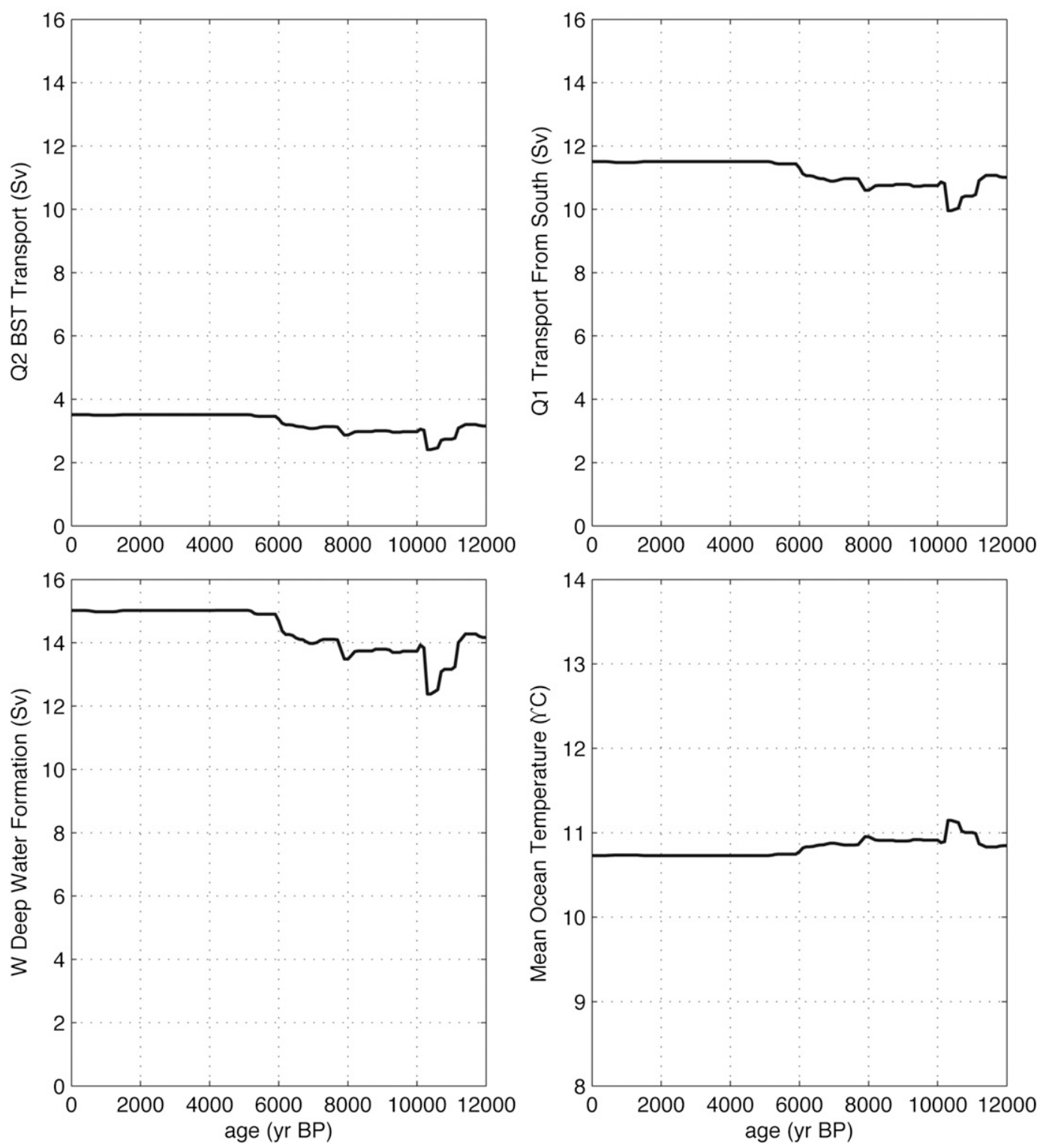

FIG. 8. As in Fig. 6, but we varied the freshwater flux forcing but not the winds (Fig. 7). (top left) We see that the sensitivity of the flow through the BS $\left(Q_{2}\right)$ to the freshwater flux variability is minimal and insignificant.

then dramatically at $\sim 6000$ cal BP, when the southern winds and freshwater fluxes were both minimal (Fig. 11). During that particular time, the flow from the Pacific to the Atlantic through the BS $\left(Q_{2}\right)$ increased. The Southern Winds remained weak until about $3000 \mathrm{cal}$ BP when they abruptly increased and the flow through BS decreases.

As shown in Fig. 11, the timing of these changes is strikingly consistent between proxies and the "predictions" of the $\mathrm{SN}$ analytical model results. The sediment proxy was converted to $\mathrm{Sv}$ for comparison with the model output by least squares linear regression $(y=0.4965 x+2.8546)$, where $x$ is the paleo data and $y$ is the model output. The correlation of the two curves determined in this way is 0.69 .

The model prediction of $Q_{2}$ represents the mean flow of the BS. The difference in variability between the two records provides a measure of the impact of local 

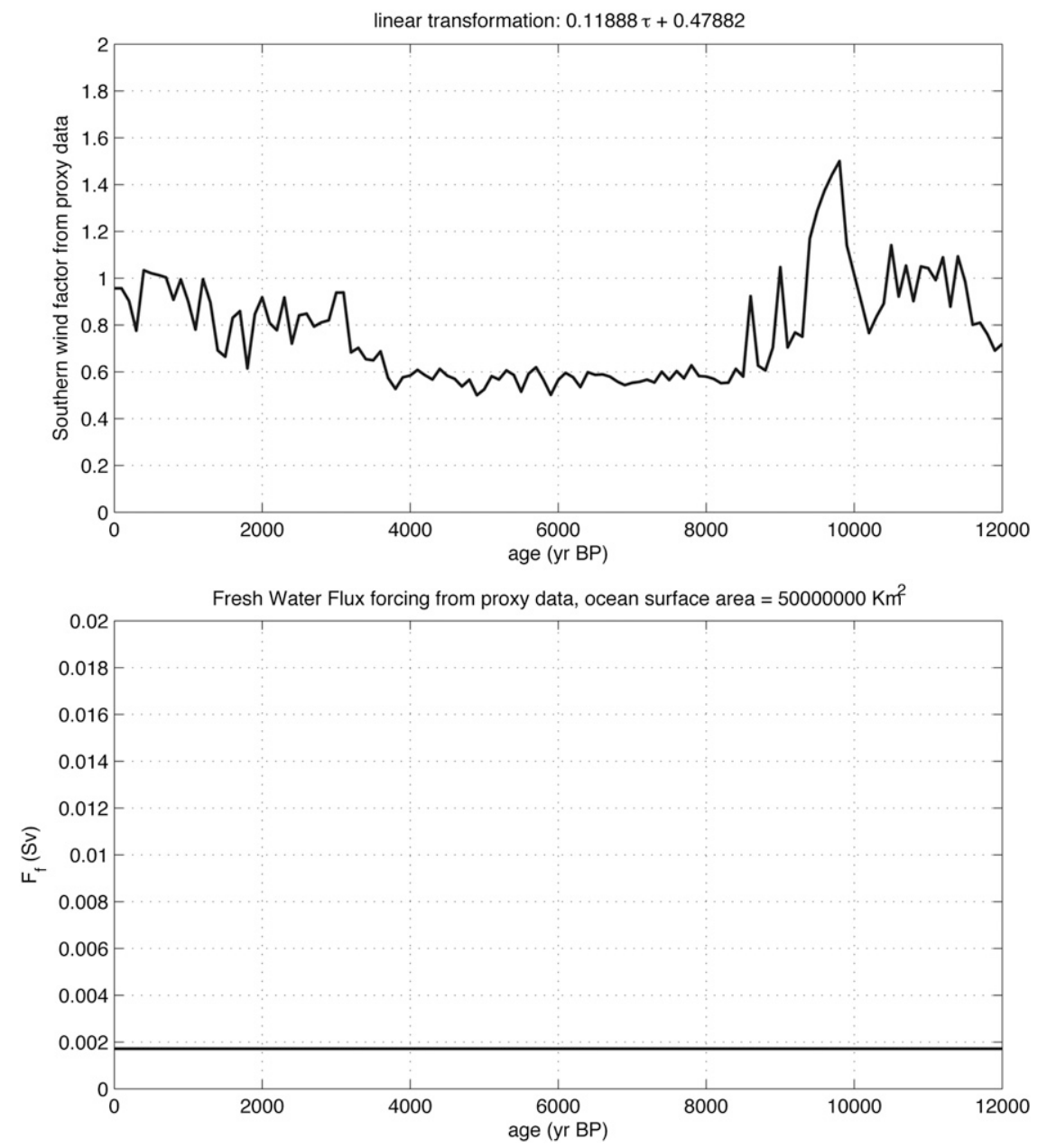

FIG. 9. The hypothetical forcing of variable winds but steady freshwater flux used for Run 3.

processes on the flow through the BS. To quantify these differences, we calculated the correlation coefficient between the two cores, which as reported above is $r=$ 0.69 , indicating that $47 \%$ of the variance in the BS record $\left(0.69^{2}\right)$ can be explained by the global winds, with the remaining variance explained by local variations and error. These observations hold despite the great distances between the core locations, which might intuitively suggest otherwise.

The results of the SN analytical model indicate that the flow through the BS after its initial flooding due to sea level rise is out of the Arctic as should be the case. As the freshwater anomalies from the melting of the Northern Hemisphere ice sheets are flushed out of the Atlantic, the strength of the AMOC grows until the flow through BS reverses, setting up the modern circulation with flow from the Pacific into the Arctic.
Comparison of the analytical model with paleoceanographic data provides an explanation for the climate response observed in the sedimentary record. On the basis of the SN analytical model and the paleoclimatic observations discussed here, we infer that the Southern Winds, which control not only the flow from the Southern Ocean to the North Atlantic, but also the flow from the Pacific to the Arctic, thus plays an important role in modulating the AMOC on millennial and glacial-interglacial time scales.

\section{c. The relative importance of form-drag in the $B S$}

This issue is not new and has been discussed by now in not less than four articles (Nof 2000; Nof and Van Gorder 2003; De Boer and Nof 2004a; Sandal and Nof 2008b). The easiest way to think about the form-drag (to be distinguished from frictional drag and form-drag 

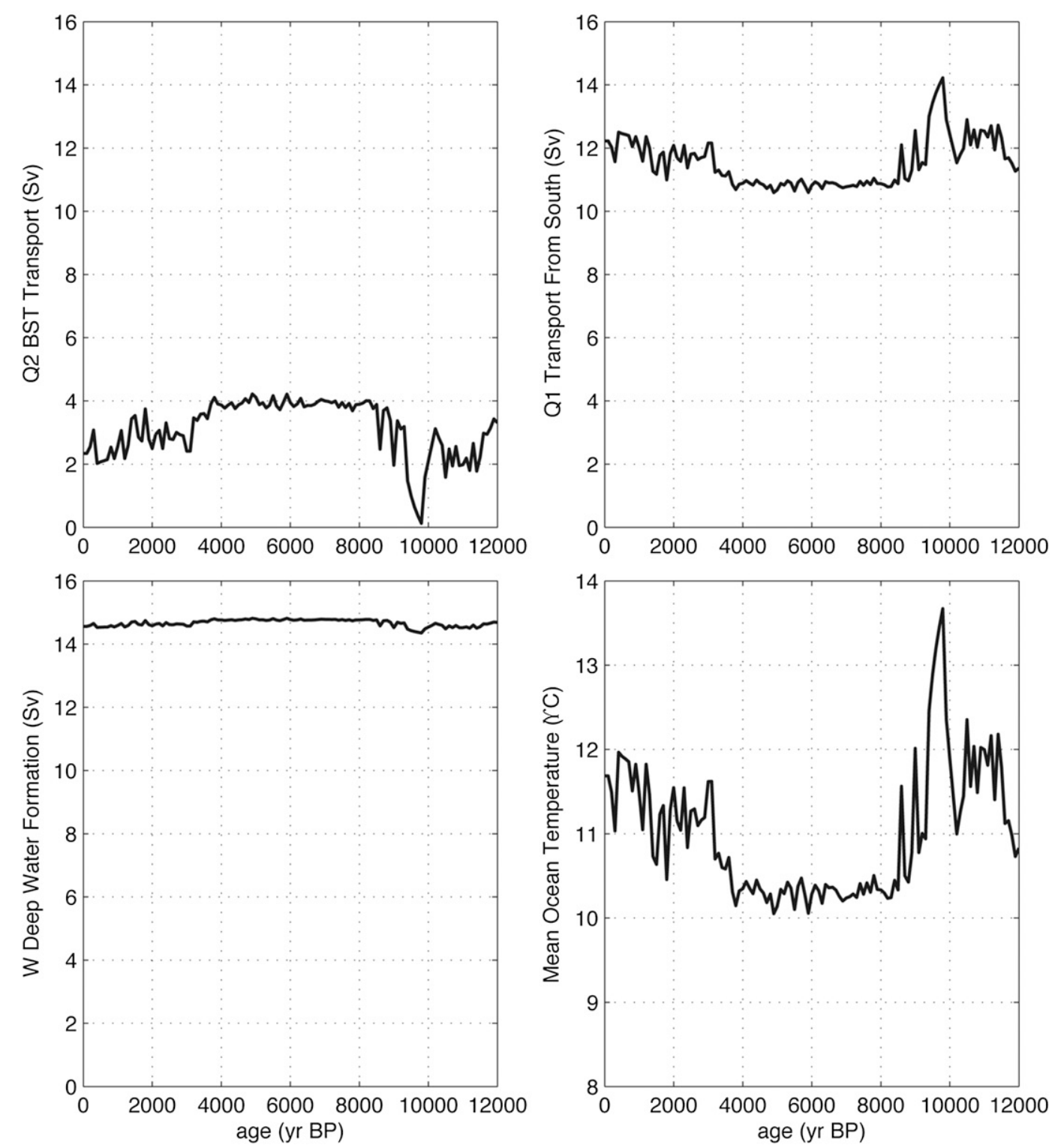

FIG. 10. As in Fig. 6, but the forcing was a hypothetical one (Fig. 7), where we varied the wind but not the freshwater flux. (top left) We see that the sensitivity of the flow through the BS $\left(Q_{2}\right)$ to the wind variability is very significant.

formulas used in numerical models) is as follows. Consider a layer-and-a-half Pacific and a layer-and-a-half Artic connected with a narrow gap and assume, initially, that there is no sill. There is flow between the two basins (through the gap) that is not affected by topography. Then introduce a sill, protruding almost all the way to the surface. A form-drag is associated with the difference in pressure acting on the upstream side of the sill and the pressure on the downstream side. Since the form-drag is not directly induced by viscosity, it can be understood using the Bernoulli, which, along a streamline, is valid with or without rotation (i.e., $f$ is not necessarily zero),

$$
\left(u^{2}+v^{2}\right) / 2+P / \rho=\text { constant } .
$$

One immediately sees that, in order for a form-drag to exist (i.e., for a pressure difference between the upstream and downstream sill sides to exist), there must be 


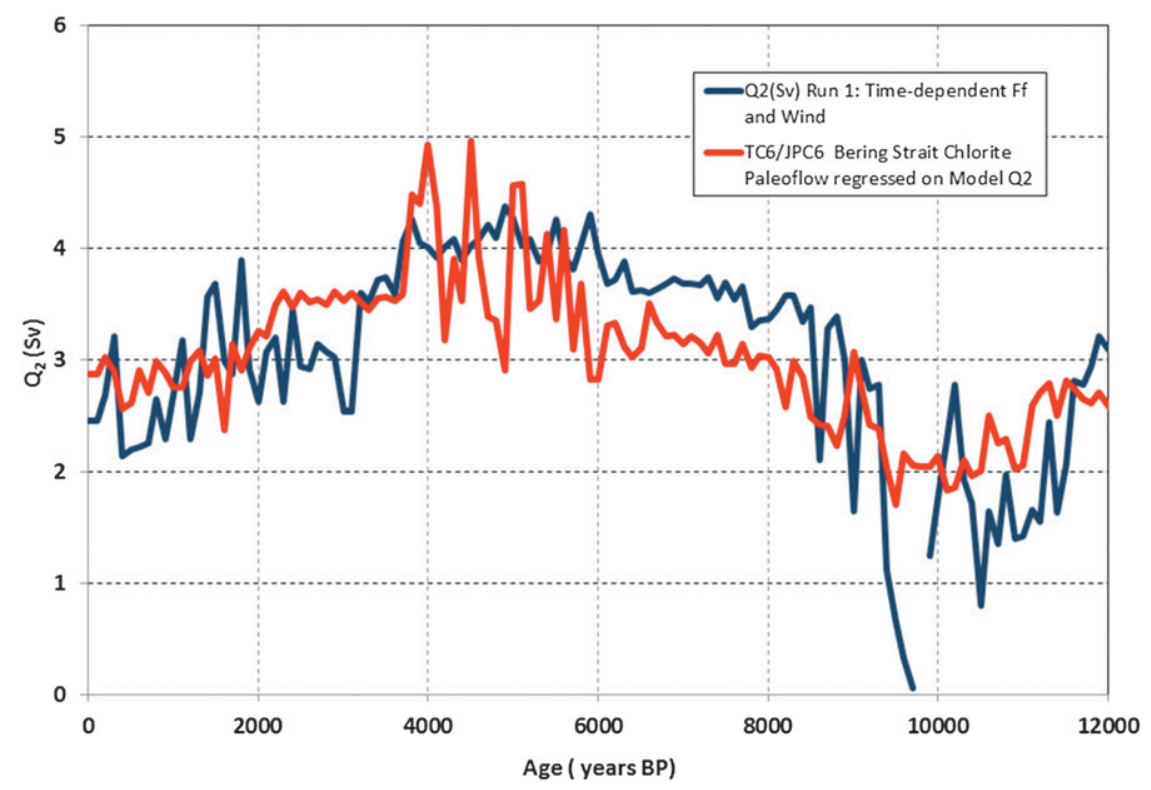

FIG. 11. A direct model-proxy data comparison for the volume flux entering the Atlantic from the BS $\left(Q_{2}\right)$ as a function of time. Blue curve is the modeled time-dependent flow calculated on the basis of the general forcing described above, whereas the red curve is the flow through the BS calculated from the sediment data. The sediment proxy was converted to Sv for comparison with the model output by least squares linear regression $(y=0.4965 x+2.8546)$, where $x$ is the paleo data and $y$ is the model output. The correlation of the two curves determined in this way is 0.69 .

a velocity difference between the upstream and downstream side of the sill. This implies that the flow field cannot be symmetrical relative to the sill if there is a form drag. More importantly, it is clear that, if there is no flow $(u=v=0)$, then there cannot possibly be any form-drag. The argument that the flow through the BS is small and close to the no-flow state was used in all of the above quoted articles to show that the form-drag is small.

It is a simple matter to determine how small the flow needs to be in order for the form- drag to be negligible. To do so, we use the Bernoulli to estimate the neglected pressure difference $(P / \rho)$ associated with the neglect of the form drag. It is of the order of $u^{2} / 2$, which, for the typical speed at the BS $\left(10 \mathrm{~cm} \mathrm{~s}^{-1}\right)$ and a depth of $50 \mathrm{~m}$, gives a neglected geostrophic transport $\left(u^{2} h^{2} / 4 f\right)$ of $0.06 \mathrm{~Sv}$, much smaller than the volume fluxes under consideration here.

\section{d. Bottom and side friction along the integration contour}

Friction along the oceanic eastern boundaries and zonal coasts is neglected in our model. (By "friction" we include here bottom, shelf and topographic form-drag along the integration contour, save the form-drag on the BS sill, which was discussed above.) The coastal currents along Alaska and Canada northern coast are, however, relatively strong so they may involve relatively large frictional forces. It turns out that this is not the case because these flows are not a part of the interhemispheric exchange that we speak about. This can be easily seen by examining Fig. 3, which shows that $75 \%$ of the wind contribution to the steady stress integral comes from the very strong southern winds, not the winds over the region that are mentioned above. Hence, all the side and bottom frictional forces combined can, at the most, introduce an error of $25 \%$, an error level acceptable in this kind of modeling.

Acknowledgments. We thank the Captain and Crew of the USCG Ice Breaker Healy. This study was supported by funds from the National Science Foundation's Office of Polar Programs (ARC 0902835 and ARC 0453846) and the Kent State University Research Council. The manuscript was improved by comments from A. de Vernal, A. Mix, and S. Lee. Mike Spall, the JPO editor, provided very useful comments on the initially submitted version. L. Keigwin provided access to core HLY0205JPC 16. All calculations related to the SN model were done by Stephen Van Gorder.

\section{REFERENCES}

Bard, E., 2002: Climate shock: Abrupt changes over millennial time scales. Phys. Today, 55, 32-38. 
Chaudhry, M. H., 1993: Open Channel Flow. Prentice-Hall, 483 pp.

De Boer, A. M., and D. Nof, 2004a: The Bering Strait's grip on the northern hemisphere climate. Deep-Sea Res. I, 51, 1347-1366.

$\longrightarrow$, and $-2004 \mathrm{~b}$ : The exhaust valve of the North Atlantic. J. Climate, 17, 417-422.

Domack, E. W., A. Leventer, R. Dunbar, F. Taylor, S. Brachfeld, and C. Sjunneskog, 2001: Chronology of the Palmer Deep site, Antarctic Peninsula: A Holocene palaeoenvironmental reference for the circum-Antarctic. Holocene, 11, 1-9.

Eittreim, S., A. Grantz, and J. Greenberg, 1982: Active geological processes in Barrow Canyon, northeast Chukchi Sea. Mar. Geol., 50, 61-76.

Gilli, A., D. Ariztegui, F. S. Anselmetti, S. Flavio, J. A. McKenzie, V. Markgraf, I. Hajdas, and R. D. McCulloch 2005: MidHolocene strengthening of the Southern Westerlies in South America-Sedimentological evidences from Lago Cardiel, Argentina $49^{\circ} \mathrm{S}$. Global Planet. Change, 49, 75-93.

Godfrey, J. S., 1989: A Sverdrup model of the depth-integrated flow for the world Ocean allowing for island circulation. Geophys. Astrophys. Fluid Dyn., 45, 89-112.

Hartmann, D. L., 1994: Global Physical Climatology. Academic Press, $411 \mathrm{pp}$.

Haug, G., D. Sigman, R. Tiedemann, T. Pedersen, and M. Sarnthein, 1999: Onset of permanent stratification in the subarctic Pacific Ocean. Nature, 401, 779-782.

Hellerman, S., and M. Rosenstein, 1983: Normal monthly wind stress over the world ocean with error estimates. J. Phys. Oceanogr., 13, 1093-1104.

Heusser, L., C. Heusser, A. Mix, and J. McManus, 2006: Chilean and Southeast Pacific paleoclimate variations during the lat glacial cycle: directly correlated pollen and $\delta^{18} \mathrm{O}$ records from ODP Site 1234. Quat. Sci. Rev., 25, 3404-3415.

Hu, A., and G. A. Meehl, 2005: Bering Strait throughflow and the thermohaline circulation. Geophys. Res. Lett., 32, L24610, doi:10.1029/2005GL024424.

- — , and W. Han, 2007: Role of the Bering Strait in the thermohaline circulation and abrupt climate change. Geophys. Res. Lett., 34, L05704, doi:10.1029/2006GL028906.

_ North Atlantic circulation on glacial sea-level changes. Nat. Geosci., 1-4, doi:10.1038/NGE0729.

Keigwin, L. D., and M. S. Cook, 2007: A role for North Pacific salinity in stabilizing North Atlantic climate. Paleoceangraphy, 22, PA3102, doi:10.1029/2007PA001420.

—, J. P. Donnelly, M. S. Cook, N. W. Driscoll, and J. BrighamGretta, 2006: Rapid sea-level rise and Holocene climate in the Chukchi Sea. Geology, 34, 861-864.

Leventer, A., E. W. Domack, E. Ishman, S. Brachfeld, C. E. McClennen, and P. Manley, 1996: 200-300 year productivity cycles in the Antarctic Peninsula region: Understanding linkages among the Sun, atmosphere, oceans, sea ice and biota. Geol. Soc. Amer. Bull., 108, 1626-1644.

,,-- A. Barkoukis, B. McAndrews, and J. Murray, 2002: Laminations from the Palmer Deep: A diatom-based interpretation. Paleoceanography, 17, 8002, doi:10.1029/ 2001PA000624.

Milne, G., and J. Mitrovica, 2008: Searching for eustacy in deglacial sea-level histories. Quat. Sci. Rev., 27, 2292-2303.

Muratli, J., Z. Chase, J. McManus, and A. Mix 2010: Ice-sheet control of continental erosion in central and southern Chile $\left(36^{\circ}-41^{\circ} \mathrm{S}\right)$ over the last 30,000 years. Quat. Sci. Rev., 23-24, 3230-3239.
Naidu, A. S., and T. C. Mowatt, 1983: Sources and dispersal patterns of clay minerals in surface sediments from the continental shelf areas off Alaska. Geol. Soc. Amer. Bull., 94, 841-854.

Nof, D., 2000: Does the wind control the import and export of the South Atlantic? J. Phys. Oceanogr., 30, 2650-2667.

— , and S. Van Gorder, 2003: Did an open Panama Isthmus correspond to an invasion of Pacific water into the Atlantic? J. Phys. Oceanogr., 33, 1324-1336.

— - - and A. De Boer, 2007: Does the Atlantic meridional overturning cell really have more than one stable steady state? Deep-Sea Res. I, 53, 2005-2021.

$\longrightarrow,-$, and L. Yu, 2010: Thoughts on a variable meridional overturning cell and a variable heat-flux to the atmosphere. Geophys. Astrophys. Fluid Dyn., 105, 1-22.

—, V. Zharkov, J. D. Ortiz, W. Arruda, N. Paldor and E. Chassignet, 2011: The arrested Agulhas retroflection. J. Mar. Res., 69, 659-691.

Ortiz, J. D., 2011: Application of Visible/near Infrared derivative spectroscopy to Arctic paleoceanography. IOP Conf. Ser.: Earth Environ. Sci., 14, 012011 doi:10.1088/1755-1315/14/1/ 012011.

—, L. Polyak, J. M. Grebmeier, D. Darby, D. D. Eberl, S. Naidu, and D. Nof, 2009: Provenance of Holocene sediment on the Chukchi-Alaskan margin based on combined diffuse spectral reflectance and quantitative X-Ray Diffraction analysis. Global Planet. Change, 68, 73-84.

Overland, J., and A. T. Roach, 1987: Northward flow in the Bering and Chukchi Seas. J. Geophys. Res., 92, 7097-7105.

Pedlosky, J., L. J. Pratt, M. A. Spall, and K. R. Helfrich, 1997: Circulation around islands and ridges. J. Mar. Res., 55, 11991251.

Pirrung, M., C.-D. Hillenbrand, B. Diekmann, D. K. Fütterer, H. Grobe, and G. Kuhn, 2002: Magnetic susceptibility and ice rafted debris in surface sediments of the Atlantic sector of the Southern Ocean. Geo. Mar. Lett., 22, 170-180, doi:10.1007/ soo367-002-0109-7.

Pratt, L. J., and M. A. Spall, 2003: A porous media theory for geostrophic flow through ridges and archipelagos. J. Phys. Oceanogr., 33, 2702-2718.

Sandal, C., and D. Nof, 2008a: A new analytical model for Heinrich events and climate instability. J. Phys. Oceanogr., 38, 451-466.

$\longrightarrow$, and $-2008 \mathrm{~b}$ : The collapse of the Bering Strait ice dam and the abrupt temperature rise in the beginning of the Holocene. J. Phys. Oceanogr., 38, 1979-1991.

— jamming of the Bering Strait. Deep-Sea Res. I, 55, 1105-1117, doi:10.1016/j.dsr.2008.04.005.

Shaffer, G., and J. Bendtsen, 1994: Role of the Bering Strait in controlling North Atlantic ocean circulation and climate. Nature, 367, 354-357.

Spall, M. A., 2000: Buoyancy-forced circulations around islands and ridges. J. Mar. Res., 58, 957-982.

Toggweiler, J. R., and B. Samuels, 1995: Effect of Drake Passage on the global thermohaline circulation. Deep-Sea Res., 42, $477-500$.

_ , and - 1993: New radiocarbon constraints on the upwelling of abyssal water to the ocean's surface. The Global Carbon Cycle, M. Heiann, Ed., NATO ASI Series, Vol. 1, SpringerVerlag, 303-331.

Villa-Martínez, R., and P. Moreno, 2007: Pollen evidence for variations in the southern margin of the westerly winds in 
SW Patagonia over the last 12600 years. Quat. Res., 68, 400409.

Weingartner, T. J., D. J. Cavalieri, K. Aagaard, and Y. Sasaki, 1998: Circulation, dense water formation and outflow on the northeast Chukchi Sea shelf. J. Geophys. Res., 103, 7647-7662.

, K. Aagaard, R. Woodgate, S. Danielson, Y. Sasaki, and D. Cavalieri, 2005: Circulation on the North Central Chukchi Sea Shelf. Deep-Sea Res. II, 52, 3150-3174.
Woodgate, R. A., K. Aagaard, and T. J. Weingartner, 2006: Interannual changes in the Bering Strait fluxes of volume, heat and freshwater between 1991 and 2004. Geophys. Res. Lett., 33, L15609, doi:10.1029/2006GL026931.

_- T. J. Weingartner, and R. Lindsay, 2010: The 2007 Bering Strait oceanic heat flux and anomalous Arctic sea-ice retreat. Geophys. Res. Lett., 37, L01602, doi:10.1029/ 2009GL041621. 